\title{
Seeing Other People
}

We get to know things in a number of different ways. For instance, among the things that I know are the following: that $4^{2}=16$; that the grass in my garden is green; that it rained last night; that the rosebush in the garden is an Indian Summer; that right now my baby daughter is miserable. The ways in which I might have come to know each of these things is a matter contested, but most would agree that naïve consciousness characterises the first four in something like the following way: I know that $4^{2}=16$ by reason alone; I know that the grass in my garden is green because I am currently enjoying a conscious experience of it; I know that it rained last night because, although I was asleep at the time, I can see that it is wet and infer that this must have been caused by rain; I know that the rosebush in the garden is an Indian Summer because my neighbour told me, and she is something of an expert on roses. In short, knowledge can be apriori, perceptual, inferential, and testimonial.

What about my knowledge that right now my baby daughter is miserable? How do I know that? Can it be assimilated to one of these four ways of gaining knowledge, or do we need a fifth category? We can straight away put aside both the apriori and knowledge by testimony. Central to my knowledge is surely a visual experience of my daughter in which no-one speaks or otherwise lets me know how she feels. So my knowledge is not apriori, nor is it based on testimony. ${ }^{1}$ This leaves us with perception, inference and our, as yet unspecified, fifth option. The fifth option is, of course, the criterial view. ${ }^{2}$ My purpose in what follows is not to adjudicate between these three.

1 Some knowledge of others' mentality is testimonial. Indeed, arguably one of the simplest ways of finding out how it is with another is by asking and being told. The point, however, is that not all knowledge of others is gotten in this way. Nor could it be. Perhaps even some knowledge of how it is with another (right now) is apriori. I will, however, limit myself to items of knowledge of others the canonical justification of which depends essentially on experience.

2 See P. M. S. Hacker, Insight and Illusion. (Oxford: Clarendon Press, 1972), and C. Wright, "Realism, Truth-Value 
Rather, I want to elaborate the perceptual view in such a way as to make it seem less obscure as to how it could possibly be true. For the idea that we know the contents of another's mind just by looking, has a tendency to be met by an incredulous stare. The idea is familiar in the Continental tradition from the discussions of, amongst others, Husserl and Merleau-Ponty, and in the analytic tradition from Wittgenstein, Dretske, McDowell and Cassam. ${ }^{3}$ But I think it fair to say that the majority of (analytic) philosophers working on the epistemology of others, and intersubjectivity more generally, accept some or other version of the inferential view, namely Simulationism or Theory Theory. ${ }^{4}$ My own conviction is that there is truth in each of these approaches. That in Links, Other Minds, and the Past" Ratio 22 (1980), pp.112-132.

3 E. Husserl, Cartesian Meditations: An Introduction to Phenomenology. Translated by D. Cairns. (The Hague: Martinus Nijhoff, 1960), §54; M. Merleau-Ponty, Phenomenology of Perception. Translated by C. Smith. (London: Routledge, 1962), p.365; L. Wittgenstein, L. Remarks on the Philosophy of Psychology, Volume II. Edited by G. H. Von Wright \& H. Nyman. Translated by C. G. Luckhardt \& M. A. E. Aue. (Oxford: Blackwell, 1980), §170; J. McDowell, “On 'The Reality of the Past'”. In his, Meaning, Knowledge and Reality (Cambridge, Massachusetts: Harvard University Press, 1998), p.305; F. Dretske, Seeing and Knowing (London: Routledge, 1969), pp.189-190; Q. Cassam, The Possibility of Knowledge (Oxford: Clarendon Press, 2007), Ch.5. Nor is the perceptual view entirely alien to cognitive psychology. For example, Hobson writes, "to perceive a smile as a smile...is to respond with feeling, in such a way that through the smile one apprehends the emotional state of the other." R. P. Hobson, "What Puts the Jointness into Joint Attention?” In N. Eilan, C. Hoerl, T. McCormack \& J. Roessler (eds.), Joint Attention: Communication and Other Minds. (Oxford: Clarendon Press, 2005), p.190.

4 See M. Davies, “The Mental Simulation Debate”. In C. Peacocke (ed.), Objectivity, Simulation and the Unity of Consciousness. (Oxford: Oxford University Press, 1994), pp.99-127. Both Simulationism and Theory Theory are usually proposed as answers to the descriptive question and, sometimes, the conceptual question (see below). But each can be stated as an answer to the epistemological question that is my main concern in this paper. I take the deployment of a tacitly known folk psychological theory, or the simulation of another subject, to be ways of moving from inputs, including perceptions of behaviour, to outputs, judgements of mentality. Whether each of these is to be referred to as 'inferential' is not really the issue. The main point is that insofar as the input into the tacit theory/simulation process is the content of a perceptual state, it is usually taken for granted that that content does 
different circumstances we get to know about others' mental states in a number of different ways, and that a search for the correct account of the epistemology of others is misguided. I will not argue for that claim here, however. Rather, I will sketch an account of the perceptual model that combines a functionalist account of mental properties with an Husserlian insight concerning perception. ${ }^{5}$ With this in view, I hope that the thought that I know that my baby daughter is miserable simply by looking, will not seem so mysterious after all.

\section{Knowledge of Others}

There are a number of interrelated philosophical questions that we can ask concerning others. The sceptical question asks how we can respond to the sceptical challenge that we really have no knowledge concerning others' minds. The epistemological question asks how, on a given occasion, our putative knowledge of another's mental life is justified. ${ }^{6}$ The descriptive question asks how we go about ascribing mental predicates to others. The conceptual question asks how it is that I am able to arrive at the very idea that another minded individual even exists, more generally it asks in what does our grasp of mental concepts consist. The experiential question asks how others are presented to me in experience. A complete philosophical theory of intersubjectivity should answer at least all of these questions.

not yet ascribe mental predicates to observed others. If it did, there would be no work for the tacit theory/simulation process to accomplish. Of course, none of that is incompatible with the claim that the inputs in a great many cases already involve mental predicates, for not all ascriptions of mental predicates to others are grounded in perception.

5 Much of Husserl's theory of intersubjectivity concerns the question, peculiar to transcendental phenomenology, of how others are constituted from within the phenomenologically reduced sphere. I will not address this issue here.

6 The sceptical and epistemological questions are not the same. Suppose that the answer to the sceptical question invokes a contextualist account of knowledge, or perhaps some kind of transcendental argument. Answering the sceptic in such a way does not yet tell us how each of our items of knowledge of others is justified. 


\section{Forthcoming in Philosophy and Phenomenological Research}

The account I will sketch is primarily an answer to the experiential, descriptive and epistemological questions. It denies, what is often treated as an assumption of the debate, that others are presented to me in experience as physical bodies exhibiting mere behaviour. Rather, so the view proposes, others are presented to me in experience as persons instantiating both mental and physical properties. $^{7}$ This answer to the experiential question provides the materials for a limited answer to the epistemological and descriptive questions. For, on at least some of those occasions on which I perceive someone as instantiating a mental property Fness, then I can come to know on purely perceptual grounds that that person is $F$. It is no part of the view that all knowledge of others' mentality is gained in this way, nor that just any instance of perceiving someone as $F$ will be sufficient for knowledge. The account is modest, in that it restricts itself to the claim that some knowledge of others' mental states is grounded perceptually. Similarly, the descriptive question of how I go about attributing mental predicates to others receives the answer that I simply report what it is that I perceive. ${ }^{8}$ Again, this is (obviously) not so for every ascription of a mental predicate to another, but the current proposal is that it is true of at least some cases.

The account also offers an answer to one version of the sceptical question. We can distinguish two sorts of scepticism about knowledge of other minds: Cartesian and Humean. ${ }^{9}$ The Cartesian sceptic points out that for any perceptual experience of another as instantiating some mental property, one could have an indiscriminable experience in which that mental property was absent, say because one was looking at a zombie. Given this fact, the Cartesian sceptic claims, I cannot rule out the possibility that each of my experiences is of this kind, and so I cannot be said to

7 Persons in the sense of P. F. Strawson, Individuals. (London: Methuen, 1959), Ch.3.

8 This is not intended to signify a commitment to an 'importation' model of the perceptual justification according to which the content of a perceptual belief is just the same as the content of the relevant perception.

9 See M. G. F. Martin, “On Being Alienated”. In T. Szabó Gendler \& J. Hawthorne (eds.), Perceptual Experience.

(Oxford: Clarendon Press, 2006), pp.354-410, for this distinction applied to external world scepticism. 
know what is going on in another's mind, or even that others have minds.

In contrast to this, the Humean sceptic claims that all we ever see of another is their behaviour and so, since behaviour is distinct from mentality, experience falls short of the other's mind. The Humean sceptic then moves from this claim to the thought that since we can never get beyond the behaviour to check that it really is the manifestation of mentality, we are never justified in believing in another's mental life.

Whilst the conclusions of these two lines of thought are the same, the paths taken by each are different. As such, we should expect different answers to these scepticisms. The perceptual account of our knowledge of others has nothing to say to the Cartesian sceptic, but it does serve to undermine the Humean line of thought. In maintaining that we (sometimes) perceive the mentality of others, it rejects the Humean's starting point that we only ever see the (mere) behaviour of others.

Whether or not the perceptual account contains the materials for an answer to the conceptual question is something to approach with care depending, as it does, on a general account of the relation between conceptual capacities and experience. The modesty of the current proposal extends to a studied silence on this issue although, as I have indicated, a full account would certainly need to broach this question. Let me simply state that I do not take any of what follows to require a stand to be taken one way or the other on the hypothesis that perceptual states have non-conceptual content.

\section{Vision, Co-Presentation and Anticipation}

Important to the account that I am going to sketch is the thought that there is more to visual experience that meets the eye. ${ }^{10}$ More specifically, the visually present is not limited to that which reflects light onto the retina to form the retinal image. Look at a solid, opaque object such as a book.

10 For simplicity I will, throughout, restrict my discussion to visual perception. 
Light is reflected off the surface of the book and is focussed by the lens onto the retina, forming an image. But, of course, light is not reflected from the the whole of the surface in this way, for the back and insides of the book are occluded by its front. Call that part of the book's surface that reflects light onto the retina its front aspect, that part of the book's surface that does not reflect light onto the retina its rear aspect, the non-surface parts of the book call its innards. Only the book's front aspect reflects light onto the retina. Should we conclude from this that only the front aspect of the book is visually present? Husserl thinks that the answer to this question must be negative.

Of necessity a physical thing can be given only "one-sidedly;"... A physical thing is necessarily given in mere "modes of appearance" in which necessarily a core of "what is actually presented" is apprehended as being surrounded by a horizon of "co-givenness" 11

Here we can distinguish between what is presented and what is co-presented (co-given) in experience. ${ }^{12}$ In our example, what is presented is the front aspect of the book. Husserl refers to that which is co-presented as a 'horizon'. Elsewhere he distinguishes between the internal and external horizons of an object: the internal horizon of an experience includes those aspects of the object (rear aspect and innards) that are co-presented. ${ }^{13}$ The external horizon includes those objects other than those presented that are co-presented as part of the surrounding environment. The current concern is

11 E. Husserl, Ideas Pertaining to a Pure Phenomenology and to a Phenomenological Philosophy, First Book: General Introduction to a Pure Phenomenology. Translated by F. Kersten. (The Hague: Martinus Nijhoff, 1982), §44.

12 In my terminology, being presented and being co-presented are both ways of being present. This may be a little misleading for those used to thinking of the co-presented as absent. Misleading but not too troublesome. I rather like Noe's phrase presence-in-absence. See, A. Noë, “Experience without the Head”. In T. Szabó Gendler \& J.

Hawthorne (eds.), Perceptual Experience. (Oxford: Clarendon Press, 2006), pp.411-433.

13 E. Husserl, Experience and Judgment: Investigations in the Genealogy of Logic. Edited by L. Landgrebe. Translated by J. S. Churchill \& K. Ameriks. (London: Routledge, 1973), §8. 
with the internal horizon of an experience of a solid, opaque object such as a book. Briefly put, the rear aspect and innards of the book are co-presented, they are visually present even though not, strictly speaking, presented. None of this is to say that what is seen is an aspect rather than a solid object. In fact, I assume that that which is seen is indeed the object itself. ${ }^{14}$ The point of introducing this terminology is simply to give us some way of noting the, undeniable, fact that my view of the object makes some of its features (its front aspect) more readily available to me than others.

I take it to be a feature of the phenomenology of visual perception that the rear aspects and innards of objects are, in some sense, visually present. Phenomenologically speaking, there is a significant difference between seeing something as a solid object, with rear aspect and innards, and seeing something merely as a surface. One might, however, accept something like this claim whilst remaining sceptical that the way in which the rear aspects and innards of a seen objects are present to one is distinctively visual. That is, one might maintain that what is visually present to one is limited to that which is presented (the front aspect), but that typically one will in addition believe or be disposed to judge the seen object to have a rear aspect and innards, and that this is what accounts for the phenomenological difference between the two experiences.

This suggestion is unconvincing, for the simple reason that even though belief, or the disposition to make the relevant judgements, is a common effect of these experiences, the phenomenology itself is belief-independent. Even if I know the objects I am seeing to be cleverly constructed façades of solid objects, it can still appear to me that I am seeing a voluminous object with a rear aspect and innards. If the phenomenology can remain in the absence of belief or disposition to judge that the object has the relevant co-presented features, then co-presentation cannot be explained in terms of belief or a disposition to judge. It might be replied that in such cases one has a 'suppressed' disposition to judge. ${ }^{15}$ But it is unclear what this amounts to in a case where 14 See P. F. Strawson, "Perception and its Objects". In G. Macdonald (ed.), Perception and Identity: Essays Presented to A. J. Ayer with his Replies. (London: MacMillan, 1979), pp.41-60. 15 See D. M. Armstrong, A Materialist Theory of Mind. (London: Routledge, 1968), pp.222-3. 
one knows the objects that one is seeing to be façades. In any case, one would expect the phenomenology in such a case to be similarly 'suppressed', but it is not. Suppose one walks into a room that one knows to be filled with trompe l'oeil paintings made to look like windows onto a country landscape. To the extent that the trompe l'oeil is successful, the items in the landscape look to be solid objects complete with rear aspects and innards. There is no suppression of the phenomenology here. True, the experience might be indiscriminable from one concerning which we are disposed to believe various things about the rear aspects of the 'objects' in view, but what does that show? Given that we know one of the experiences to involve the perception of trompe l'oeil paintings, we should expect our dispositions to make various judgements about our environment to differ. As another example, consider fig $1:^{16}$
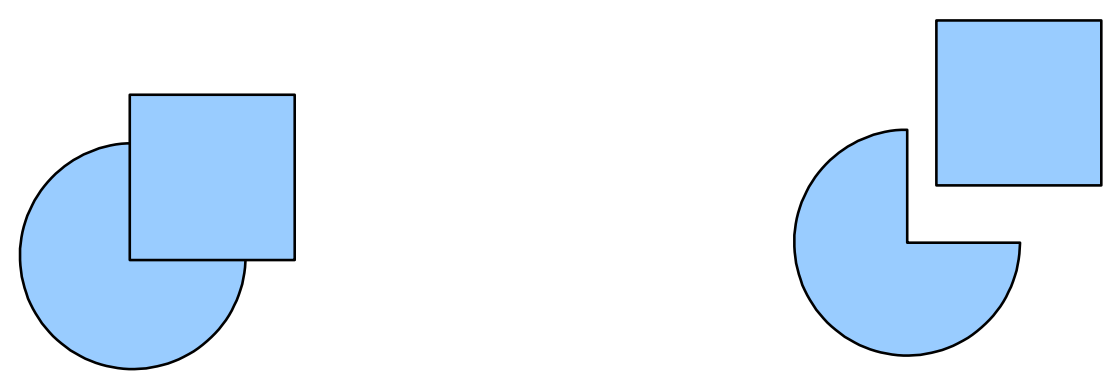

fig 1

That part of the 'circle' which is 'obscured' by the square is co-present. However, we are in no way disposed to judge there to be any such part of the circle, since we know it to be a two dimensional picture with no hidden parts. With pictures, there is a clear sense in which, although much is copresented, that co-presentation is illusory since what we see is what we get. It seems implausible to suggest that we have a disposition, albeit a suppressed one, to judge that the 'circle' has a hidden

16 I have adapted the example used by Noë (2006), p.415. 
part.

What then is co-presentation? Husserl often uses the term 'anticipation' to describe the way in which the merely co-presented is present in perceptual experience,

there belongs to every external perception its reference from the "genuinely perceived" sides of the object of perception to the sides "also meant" - not yet perceived, but only anticipated and, at first, with a non-intuitional emptiness...the perception has horizons made up of other possibilities of perception, as perceptions that we could have, if we actively directed the course of perception otherwise ${ }^{17}$

In these terms, the front aspect of an object is "genuinely perceived". However its other features (rear aspect and innards) are also visually present by way of being anticipated. This anticipation is, in part, an anticipation of how the object will appear in subsequent experiences if, for example, I move my head to the left. These anticipations count as genuinely perceptual, rather than as merely beliefs concerning my future experiences, but they lack the "intuitional fullness" of the fully presented. The non-intuitional emptiness of the merely co-presented can be brought into intuitional fullness precisely by, say, moving one's head to the left and making the previously co-presented rear aspect actually presented. Perceptual anticipations have, we can say, an 'if...then...' structure. Again, Husserl

I recognise that a hidden intentional "if-then" relation is at work here: the exhibitings must occur in a certain systematic order; it is in this way that they are indicated in advance, in expectation, in the course of a harmonious perception. ${ }^{18}$

17 Husserl (1960), §19.

18 E. Husserl, The Crisis of European Sciences and Transcendental Phenomenology. Translated by D. Carr. (Evanston: Northwestern University Press, 1970), §47. 
This notion of a perceptual anticipation might be cashed out in a number of ways depending on one's general account of perception. I will mention just two: intentionalism and enactivism. ${ }^{19}$ To accommodate co-presentation, the intentionalist will need to distinguish between two different types of perceptual intending. One way to do this might be to say that the presented has qualitative features that the merely co-presented lacks, another would be to say that whilst the front aspect is intended as determinate, the merely co-presented is intended as indeterminate in various ways. ${ }^{20}$ On an enactivist picture of perception, the merely co-presented might be understood in terms of sensori-motor dispositions, or knowledge thereof. As Noë puts it, 'The presence of the tomato to me as a voluminous whole consists in my knowledge of the sensory effects of my movements in relation to the tomato. ${ }^{21}$ This account would naturally capture Husserl's talk of anticipation something's being co-present to one is, in part, a matter of one's having various (perceptual) expectations as to how it will appear, and otherwise behave, given changes in the environment, especially one's own position. I have no wish to take sides here on the debate between the different accounts of perception. ${ }^{22}$ For the remainder of this paper, I will continue to speak of the copresented and of the anticipatory structure of perceptual experience, simply assuming that some

19 On intentionalism, see T. Crane, “Intentionalism”. In B. McLaughlin \& A. Beckermann(eds.), Oxford Handbook to the Philosophy of Mind (Oxford: Oxford University Press, 2009). On enactivism, see A. Noë, A. Action in Perception. (Cambridge, Massachusetts: MIT Press, 2004). These two might plausibly be thought to represent contemporary versions of Husserl's and Merleau-Ponty's positions respectively.

20 Each of these is present in Husserl. See Husserl (1960), §19, and Husserl (1982), §44.

21 Noë (2006), p.423.

22 The obvious similarity between enactivism and phenomenalism invites the objection that the enactivist account implausibly allows the following possibility as a case of veridical perception: only the front aspect exists, the rear aspect popping into existence only when I move in the relevant way. Whether this objection is successful is a question that I will not broach here. 
account of these phenomenological features of perception is available. ${ }^{23}$

\section{Co-Presentation and Other Minds}

Perhaps the way in which other minds are present in experience is like the way in which the rear aspect of the book is. Might it be that whilst only behaviour is presented in visual experience mentality is co-presented? Just as the rear aspect of the book is visually present without being visually presented, so another's misery is visually present even though only their frown is visually presented. This view would count as a perceptual account of our access to others' mental states, but would also respect the deep seated intuition that others' mental states are in some sense hidden from view.

Two objections can be raised to this analogy between the co-presentation of an object's rear aspect and the way in which others are given in experience. The first points out that (a great many) mental states are functional/dispositional properties and that it is implausible to suppose that such properties enter into the content of perception. ${ }^{24}$ One way of fleshing out this objection would be to

23 I earlier said that my account would remain neutral over the question of non-conceptual content. With this in mind, one might wonder whether a non-conceptual account can be given of perceptual anticipation. For one might suppose that only conceptual structure could make perceptual content robust enough to support conditionals. One possibility, of course, is the enactivist proposal that perceptual content be understood in terms of sensori-motor dispositions, which I take to be non-conceptual. Another would be the view that the conditional character of perceptual content be understood as the presence to the subject of objects' modal properties. In general, I think that the onus is on the conceptualist to say exactly what it is that disqualifies non-conceptual content to be most appropriately conceptually articulated in conditional terms.

24 See the distinction between the 'dispositional' and the 'manifest' in N. Goodman, Fact, Fiction, and Forecast, third edition. (Hassocks, Sussex: Harvester Press, 1979), pp.40-49. Although he does not endorse the claim, the discussion in J. Campbell, Reference and Consciousness. Oxford: Clarendon Press, 2002), Ch.12, is pertinent. Also see the discussion in J. Campbell, “Molyneux's Question”, Philosophical Issues 7 (1995), pp.301-318, especially 
say that perception gives us an object's properties 'in one go', and since functional/dispositional properties are both modally and temporally extended, they are not well suited to enter into the content of perceptual experience. ${ }^{25}$ In this respect, mental properties differ from objects' rear aspects and their properties, so it as at this point that the proposed analogy breaks down. This, however, is not a good way to phrase the objection, since it is possible to respond that although functional properties are individuated, in part, by how they would make their possessors behave given certain merely possible, or future, conditions, it does not follow that the property itself is not wholly present at any one moment in time. The objection is better put epistemically: the analogy with rear aspects and their properties breaks down since, whilst the rear aspect is simply a front aspect turned in the wrong direction and so can be known at a glance, a functional/dispositional property cannot. ${ }^{26}$ Such a property can only be known to be instanced by engaging in a series of 'experiments' to determine whether the object behaves in the ways definitive of the property. If the functional definition states that it will behave in way $\mathrm{W}$ in circumstance $\mathrm{C}$, then we need to place it in circumstance $\mathrm{C}$ and see what happens.

The second objection is raised by Husserl himself. Discussing the analogy between the way in which rear aspects are present and the way in which another's mentality is, he points out that

experiencing someone else cannot be a matter of just this kind of appresentation [copresentation]...Appresentation of this sort involves the possibility of verification by a corresponding fulfilling presentation (the back becomes front); whereas, in the case of that section 2. The account there sketched by Campbell is in some ways closely related to the one I outline in this paper.

25 Those who take colours and other secondary properties to be dispositional in nature will not be moved by this objection. However, that does not mean that we don't need an account of why we shouldn't be moved by it.

26 The claim that the state of the rear aspect of an object can be known at a glance should not be thought to involve any commitment to the claim that perceptual states represent all detail 'at once'. For a glance may be more or less extended in time. Thus, no stand need be taken on the question as to whether perception is 'rich' or 'gappy'. 
appresentation which would lead over into the other original sphere, such verification must be excluded a priori. ${ }^{27}$

The co-presentation of the book's rear aspect can be verified by an appropriately related presentation of it as a front aspect. What it is for the rear aspect to be co-presented is, in part, for one to to perceptually anticipate how the book will look if one moves one's head and brings the copresented into full presentation. None of this can be said in the case of the experience of another. When seeing another's frown, I cannot get a better view in order to bring the putatively copresented misery into full presentation. The mentality of another is never any more than copresented. So, again, the analogy with the co-presentation of rear aspects breaks down.

\section{4. 'Latching on' to a Functional Role}

These objections can be answered together. A good start is to consider Husserl's own answer to the second objection. His idea is that what is anticipated in the case of co-presented mentality are further presentations of behaviour that co-present related mentality. For example, if your frown copresents misery then I will anticipate further behaviour that co-presents appropriately related states, such as for example self-pity. ${ }^{28}$ In this way, a co-presented horizon can be verified in another's "changing but incessantly harmonious behaviour" 29 We can regard one's co-presentations of another's mentality to be fulfilled not, as with the rear aspect of the book, by the co-presented 27 Husserl (1960), §50.

28 "Regarding experience of someone else, it is clear that its fulfillingly verifying continuation can ensue only by means of new appresentations that proceed in a synthetically harmonious fashion, and only by virtue of the manner in which these presentations owe their existence-value to their motivational connexion with the changing presentations proper" Husserl (1960), §52.

29 Husserl (1960), §52. 
becoming presented, but by the co-presented and presented taking part in a harmonious experience.

We can say more than this, however. Suppose, with the first objection, that some mental properties are individuated by their functional roles. It may be that one's perceptual presentations and anticipations 'latch onto', or match, the functional role of another's mental state. If we define mental state $M$ as that property one has if one will behave in way $B$ given input $I$, and in one's perception of another one perceptually anticipates that if $I$ occurs then one will perceive $B$, then one's perceptual states 'latch onto' property $M$. This, I suggest, is one way of perceiving a person as instantiating mental property $M$. Indeed, I propose the following general principle L:

L: For any object $O$ and functional property $F$, if the perceptual anticipations in one's perception of $O$ 'latch onto' the functional role definitive of $F$, then one perceives $O$ as being $F{ }^{30}$

We can immediately see how this account answers the first objection. For $\mathrm{L}$ is an account of how dispositional/functional properties enter into the content of experience. The 'if...then...' structure of perceptual anticipations lets us see how perception can put us in touch with functional properties extended, if indeed they are, both temporally and modally. ${ }^{31}$

In addition, Principle L is consonant with Husserl's response to the second objection. It is not a requirement on co-presentation that the co-presented be capable of being presented. All that is

30 Notice two things. First, L is a conditional not a biconditional. Second, L says nothing concerning mental events.

31 Incidentally, contra the letter of the first objection, I think it plausible that all empirical properties are individuated by their functional roles. See S. Shoemaker, "Causality and Properties” and "Identity, Properties, and Causality". Both in his, Identity, Cause, and Mind: Philosophical Essays. (Cambridge: Cambridge University Press, 1984). Also see A. Whittle, “A Functionalist Theory of Properties”. Philosophy and Phenomenological Research 77:1 (2008), pp.59-82. 
required is that one's perception of the object be harmonious. If one's perceptual anticipations fail to 'latch onto' the functional role properly, then given the right circumstances one's experience will be discordant. One's presentations will fail to accord with one's previous co-presentations. In such a case, one has perceived the object as having a property that it did not in fact have.

Given the picture I have been sketching, and principle L in particular, we are in a position to see how to determine whether mentality or mere behaviour is perceived. We can determine which property one perceives a person as having by determining what perceptual anticipations one has. This is a matter open to empirical and phenomenological confirmation and, although I won't make the case here, it seems likely to me that given such an account we often see people as being in various mental conditions. ${ }^{32}$ This provides a modest answer to the experiential, descriptive and epistemological questions of others, and provides an answer to the Humean version of the sceptical question. The experiential question is answered by saying that, at least on some occasions, we see others as persons, possessing both mental and physical properties. The descriptive question is answered by saying that we ascribe mental predicates to others simply be reporting our perceptual experiences. The epistemological question is answered by the claim that on at least some of those occasions in which I perceive another as instantiating some mental property I can come to know, purely on perceptual grounds, that that person does indeed have that mental property. The Humean version of the sceptical question is answered by the rejection of the sceptical premise that the mentality of another is forever out of reach of perceptual experience.

\section{Objections}

32 The empirical question is complicated by the fact that beliefs or dispositions to judge can replicate some of the features of genuine perceptual anticipations. This is not a problem in principle to determining which property is perceived, however. 


\subsection{Functionalism and Circularity}

Given that this is a functionalist rather than behaviourist theory, the functional role of a mental property will make reference to other mental properties. One might, then, have concerns about the explanatory value of the account - doesn't this account of how mental properties enter into the content of perception already presuppose that they so enter? If so, haven't I failed to dislodge the incredulous stare? Although this might appear troubling, such appearances are deceptive. What it is for these other mental properties to enter into the content of perception will be similarly given by L. The sort of apparent circularity that ensues is of no more consequence than the familiar sort incurred by any functionalist account, given the simultaneous definition of mental states.

\subsection{The Epistemological Question}

Perhaps a more serious concern is that the account, despite its intentions, fails to answer the epistemological question after all. We can suppose, so this objection might run, that seeing something can (in the right circumstances) ground knowledge, or at least justified judgements, concerning that thing. So, seeing a book before me, I will be justified in judging that there is a book before me. However, it is far from clear that something's being merely co-presented in perceptual experience is ever sufficient for justified judgement. Can we say that, seeing the book from the front, I am justified on purely perceptual grounds in judging that the book has a rear aspect? If we are reluctant to say so, then why would the co-presentation of someone's mentality be sufficient to ground justified judgements, let alone knowledge? This is especially so given that the way in which another's mentality is present seems essentially to involve co-presentation in a way that the rear aspect of the book does not. 
There are at least two ways to respond to this challenge. The first begins with the point that there is something rather odd about the idea that perception alone is sufficient for justified belief that there is a book before me but not sufficient for justified belief that the book before me has a rear aspect. This is for the reason that books, being solid objects, of necessity have rear aspects. There is no contradiction in the idea that one is justified in believing that $\mathrm{P}$ but not that $\mathrm{Q}$ on purely perceptual grounds, even though Q follows from P. However, there is certainly some plausibility in the thought that my knowing that there is a book before me is partly constituted by, or at least requires, my knowing that the thing before me has a rear aspect. There is, then some pressure on this challenger to explain how his or her position can possibly be right.

Perhaps a more stable position from which to mount this kind of challenge is one which denies, for just this reason, that I am justified on purely perceptual grounds in believing that there is a book before me. The challenge would now be stated in the following way: Perception of the book justifies me in forming various beliefs about the front aspect. Beliefs concerning the rear aspect, the innards, indeed the book as a whole, require for their justification something in addition. This is now a much more radical position that the challenger is assuming. It is at this point that we may want to simply dig in our heels and maintain that the implausibility of this position gives us reason to backtrack to the original claim that one can be justified in believing in the rear aspect of the book on perceptual grounds alone. ${ }^{33}$ Indeed, given that, as I have been assuming, what is seen, the object

33 This is admittedly a little quick. The challenger's position might be fleshed out in the following way: (1) Objects are only ever mediately perceived, since we perceive objects in virtue of perceiving their front aspects (see F. Jackson, Perception. (Cambridge: Cambridge University Press, 1977), and J. L. Bermúdez, "Naturalized Sense Data". Philosophy and Phenomenological Research 61:2 (2000), pp.353-374.). (2) Perceptually grounded knowledge, or justified belief, requires immediate not simply mediate perception of an object. I would take issue with both elements of this view, but in particular with (2). For one thing, as Bermúdez himself argues, (1) is consistent with perception being sufficient to secure demonstrative reference to the whole object. If mediate perception is sufficient for demonstrative reference what reason is there for holding that it is insufficient for justified belief in the object 
of perception, is the book itself rather than merely a front aspect, this backtracking seems entirely natural. We simply need insist that that in which one is justified in believing on the basis of perception, is that which is seen, i.e. the object.

The second response involves pointing out exactly how co-presentation in general is related to principle L. For the challenge wrongly suggests that the way in which a mental property is present in experience is (roughly) the same as the way in which an object's rear aspect is. But this was not the point of the analogy. The rear aspects of objects are present by way of being copresented. But, according to $\mathrm{L}$, this is not true of mental properties. Seeing an object as having a (functional) mental property involves the presentation of some things, the manifest behaviour, and the co-presentation of others, if you like the merely dispositional aspects. The point of the analogy with the way in which rear aspects are present was simply to open us up the possibility that these merely dispositional aspects really do enter into the experience. It is consistent with the view I am sketching that the epistemological questions regarding rear aspects are very different from the epistemological questions regarding perceived functional properties. On the present proposal, L is simultaneously an account of how functional properties enter into the content of experience and of how they can be known to be instantiated on purely perceptual grounds. Claiming that copresentation is not sufficient for knowledge is not enough to dislodge this proposal, since functional properties are not merely co-presented. Rather, they enter into the content of perception by being partly presented and partly co-presented. In this respect, their presence to experience is unlike the presence of rear aspects.

\subsection{Indeterminacy}

Is there a problem concerning the indeterminacy of seen mental properties? If something is ever co-

demonstrated? 
presented it is surely only ever indeterminately so. But functional roles are fully determinate. So how do we ever 'latch on'? It must be admitted that co-presentation brings with it a level of indeterminacy. This is something that Husserl recognises and incorporates into his account of the inner horizon of a perceptual experience. On his account, the co-presented has a

more or less vague indeterminateness...the indeterminateness necessarily signifies a determinableness which has a rigorously prescribed style. It points ahead to possible perceptual multiplicities which, merging continuously into one another, join together to make up the unity of one perception in which the continuously enduring physical thing is always showing some new "sides"...the indeterminacies become more precisely determined and are themselves eventually converted into clearly given determinations; conversely, to be sure, the clear is changed again into the unclear, the presented into the non-presented, etc...Necessarily there always remains a horizon of determinable indeterminateness ${ }^{34}$

The rear aspect of the book is co-presented, but only indeterminately so. For example, perhaps it is co-presented as being coloured but not as being any one determinate colour. This interlocks with the account of perceptual anticipations. Part of what is anticipated in the case of a co-presented rear aspect is that, given certain bodily or environmental movements, the indeterminate will 'become more precisely determined'.

That which is co-presented in the perception of someone as instantiating a (functional) mental property is similarly indeterminate. Let us suppose that the property of being miserable is a determinable with exactly two determinates, being abjectly miserable and being tolerably miserable. These two determinables, being distinct properties, will be individuated by distinct functional roles. But it might be that one's perception of a person as miserable is indeterminate as

34 Husserl (1982), §44. 
between abject and tolerable misery. It may be that this level of determinacy will only be brought to light given some future situation in which the person's behaviour will accord with the one rather than the other functional role.

On a functionalist account, one property $F^{l}$ ness determines another Fness when the causal powers bestowed upon the object by Fness are a proper subset of those bestowed by $F^{l}$ ness. ${ }^{35}$ Given principle L, we should say that one sees a person as having the determinable property Fness if one's perceptual anticipations 'latch onto' the subset. If further experience serves to further determine exactly which property is perceived, this is a matter of one's perceptual anticipations 'latching onto' a fuller range of $F^{l}$ ness' functional role. If, as seems rather plausible given the complexity of mental states' functional roles, one's perceptual anticipations never 'latch onto' the complete functional role of an instantiated mental property, then one will never see a person as instantiating the fully determinate mental property that they do. And this is an intuitive result, the perception of another's mentality always leaves room for further discovery about another's exact state of mind. Given that when one instantiates a fully determinate mental property, one also instantiates the determinables of which it is a determinate, one can know on perceptual grounds that a person instantiates the determinable without knowing exactly which determinates are instantiated. So the indeterminacy that comes hand in hand with the notion of co-presentation is no barrier to the current proposal's claim to provide an answer, in at least some cases, to the epistemological question concerning others.

\subsection{A Threat of Collapse}

In the debate between theory theorists and simulationists some have argued that the distinction

35 See A. Whittle, “The Co-Instantiation Thesis". Australasian Journal of Philosophy 85:1 (2007), pp.61-79. 
between these two positions collapses. ${ }^{36}$ The concern is that once we have in view what the deployment of a tacitly known theory consists in, it may well turn out that simulating someone's mental life simply is the deployment of a tacitly known folk psychological theory. Might something similar occur in the present case?

Given functionalism it is natural, although perhaps not obligatory, to see mastery of a mental concept $F$ as possession of a folk psychological theory that embeds the functional role that individuates Fness. Furthermore, this line of thought runs, it is plausible to suppose that only perceivers with a certain level of conceptual mastery can be correctly described as seeing a person as instantiating a given range of mental properties. Now the threat of collapse can be sensed. Might it not turn out that perceiving someone as instantiating the mental property Fness just is the deployment of a tacitly known folk psychological theory that embeds the concept $F$ ? If so, then it looks as though I have simply described a version of the theory theory.

It is true that, via the link with functionalism, there is some affinity between theory theory and the view that I have been sketching. However, the threatened collapse relies on some weighty assumptions concerning the relation of concepts to perceptual experience. Taking on a functionalist account of the mastery of psychological concepts, it goes on to assume two things. First, that seeing an object as instantiating a mental property $F$ requires one to be in possession of the concept $F$. Second, that perceptual appearances can be constituted by the deployment of a tacitly known theory.

I have already declared my intention to remain neutral on the relation between conceptual capacities and perceptual content. Nevertheless, the following two points seem to me to be worth consideration. First, although there is a significant pull in the direction of thinking that some mental properties are only even potentially visible to the conceptually sophisticated, for other mental properties the pull is less powerful. This is especially so for such 'low level' mind-reading tasks as 36 See Davies (1994). 
the detection of emotion which, quite plausibly, are in operation from a very early age. ${ }^{37}$

Second it is unclear why the theory theory is to be considered the default position here. In so far as the deployment of a tacitly known theory is something that is unavailable to consciousness, as I presume it to be in the sorts of cases that are at issue, the point might, for all that has been said, be incorporated into the perceptual view. That is, it could be treated as further articulating what it is to perceive an object as possessing a functional property. Of course, it is usually assumed that perception provides some of the inputs into the tacit theory, and that these inputs do not yet ascribe mental states to others. The present proposal would depart from the standard construal of the theory theory, by viewing the deployment of the tacit theory as itself partly constituting the perceptual experience the content of which is another person and their mental states. Obviously this raises a whole host of issues that cannot be treated here, and I do not mean to suggest that this is the right way to view things. The point is simply that it cannot just be assumed that the theory theory proposal and the perceptual model are actually at odds with each other. It is no part of the present account that theory theory, or for that matter simulationism, is false. Rather, the intention is to make a case that the perceptual model might, in at least some cases, be true.

\section{Expression and Manifestation}

It is usual for defenders of a perceptual account of our knowledge of others mentality to lean heavily on the idea that behaviour expresses mentality. ${ }^{38}$ My reluctance to follow suit is partly due

37 For the low-level/high-level distinction, see A. Goldman, Simulating Minds: The Philosophy, Psychology, and Neuroscience of Mindreading. (Oxford: Oxford University Press, 2006). For early awareness of others' emotional states, see M. Legerstee, and J. Varghese, “The Role of Maternal Affect Mirroring on Social Expectancies in ThreeMonth-Old Infants”. Child Development 72 (2001), pp.1301-1313.

38 See, for example, S. Overgaard, "Rethinking Other Minds: Wittgenstein and Levinas on Expression”. Inquiry 48:3 (2005), pp.249-274, and A. Rudd, Expressing the World: Skepticism, Wittgenstein, and Heidegger. (Chicago: Open 
to the concern that the crucial notion is generally left somewhat opaque. The perceptual account of the epistemological question of others that I have been outlining uses no such terminology. However, there is nothing wrong with using the word 'express' in this context. Indeed, the functionalist account that I have been elaborating give us some more terminology to play with. For it is common to speak of dispositions and their manifestations. Dispositional, or functional, mental states are manifested in a person's behaviour. We can also quite happily say that that behaviour is expressive of that mental state. Thanks to the anticipatory structure of visual perception, when we see such expressive behaviour we will often also be co-presented with the unmanifested, unexpressed, 'merely dispositional' aspects of the property. It is this idea that is key in attaining a clearer account of how it could be true that we can know another's mental condition simply by looking. ${ }^{39}$

Court, 2003), Part 2.

39 Thanks to audiences in Stirling, Edinburgh, Manchester, Cambridge and London. I have had useful discussions about these ideas with many people including, Tom Avery, Andy Clark, Anil Gomes, Adrian Haddock, David Liggins, Mike Martin, Matt Nudds, Lucy O'Brien, Tom Smith, Peter Sullivan, Pepa Toribio, Michael Wheeler and Ann Whittle. 